\title{
Increasing the directivity of a microstrip patch array by genetic optimization
}

\author{
Jeevani Windhya Jayasinghe ${ }^{1^{*}}$, Disala Nilanthaka Uduwawala ${ }^{2}$ and Jaume Anguera ${ }^{3,4}$ \\ ${ }^{1}$ Department of Electronics, Faculty of Applied Sciences, Wayamba University of Sri Lanka, Kuliyapitiya. \\ ${ }^{2}$ Department of Electrical and Electronic Engineering, Faculty of Engineering, University of Peradeniya, Peradeniya. \\ ${ }^{3}$ Technology and Intellectual Property Rights Department, Fractus, Barcelona, Spain. \\ ${ }^{4}$ Electronics and Communications Department, Universitat Ramon Llull, Barcelona, Spain.
}

Revised: 31 March 2014; Accepted: 17 October 2014

\begin{abstract}
Conventional single element microstrip patch antennae have a low directivity $(6-8 \mathrm{~dB})$. In order to increase the directivity, an array of microstrip patches can be used. It may be possible to further improve the performance of arrays by applying genetic algorithms (GA). This paper presents a method to increase the directivity of a $2 \times 1$ patch array with broadside radiation using GA. The proposed GA method divides the patch area into different cells, taking into account that cells have a small overlap area between them. The patch array is etched on a substrate with a relative permittivity of 3.38 and a thickness of $1.52 \mathrm{~mm}$. The antenna operates at $4 \mathrm{GHz}$ resulting in a directivity of $10.9 \mathrm{~dB}$. The specialty of this design is the use of GA to select the inter-element spacing, optimized shape and the feeding position instead of a known shape and a fixed inset length of feeding. The results show that the directivity of the genetic array is larger than that of the conventional array with the same overall dimensions, which resonates at the same frequency.
\end{abstract}

Keywords: Genetic algorithms, microstrip arrays, microstrip patch antenna.

\section{INTRODUCTION}

Conventional single element microstrip patch antennae have a moderate directivity of about $6-8 \mathrm{~dB}$ (Balanis, 2005). The design of a high-directivity microstrip patch antenna is a challenging task because a classical patch such as the square patch presents a broadside pattern at its fundamental mode $\left(\mathrm{TM}_{10}\right.$ or $\left.\mathrm{TM}_{01}\right)$ with a low directivity. At the $\mathrm{TM}_{20}$ or $\mathrm{TM}_{02}$ there is a null in the broadside direction. A broadside pattern can be found at a higher order mode $\left(\mathrm{TM}_{30}\right)$, but the directivity is again limited, as the pattern presents high secondary lobes.
Various methods to improve the directivity of a patch antenna have been reported in literature. One such method is the use of higher order modes of fractal-like antennae such as Sierpinski (Anguera et al., 2001; 2003a), Koch (Borja et al., 2000; Romeu et al., 2000; Anguera et al., 2008), and Hilbert (Anguera et al., 2003b). Another technique to increase the directivity is the use of stacked patch antennas (Anguera et al., 2004). In addition to the above, high-directivity antennae based on superstrates (Foroozesh \& Shafai, 2012; Pirhadi et al., 2012), zeroindex metamaterial (Zhou et al., 2009), electromagnetic band gap resonator (Cheype et al., 2002), modified peano space-filling curve (El-Khouly et al., 2007), photonic band-gap materials (Yang et al., 1997) and partially reflective surfaces (Weily et al., 2005) have also appeared in the field. Moreover, publications by Jayasinghe et al. (2013a;b) propose the design of a high-directivity microstrip patch antenna to replace a $2 \times 1$ and a $4 \times 1$ conventional patch arrays by avoiding feeding networks. In contrast, the present study proposes applying genetic algorithms (GA) on an array, and in particular, to each of the elements of a $2 \times 1$ array. The objectives of this study are to find the most suitable patch geometry, inset feeding length and inter-element spacing of a $2 \times 1$ array, while keeping the substrate height small $(\sim 0.02 \lambda)$ in order to further improve the directivity compared to a square element array having the same dimensions.

GA is a powerful optimization technique that has been shown to be useful in a wide area of electromagnetics. Nearly 20 years ago, the genetic optimization of a set of metallic strips to obtain desired radiation parameters was discussed by Haupt (1995). GA has been used to 
design compact and multiband arrays (Paras \& Gangwar, 2011), high-gain and wideband arrays (Feng et al., 2013), thinned arrays (Jain \& Mani, 2011), switched beam antenna arrays (Mitilineos et al., 2004) and low radar cross section arrays (Zhu et al., 2012). Further, GA has been incorporated in arrays to reduce side lobe levels (Laseetha \& Sukanesh, 2011; Patel \& Alad, 2013) to increase directivity (Siakavara, 2010), locate defective elements (Rodríguez et al., 2000) and for beam scanning (Tokan \& GÄunes, 2009). Moreover, the design of radiation characteristics of a patch array in terms of side-lobe level, main-lobe half-power beamwidth and dynamic range is also available in literature (Coevorden et al., 2005).

However, to the authors' knowledge no references have been found regarding optimizing the antenna geometry of a microstrip patch array, to improve the directivity in comparison to the same array using square elements. In this study, GA is used to design a highdirectivity patch array by optimizing the inter-element spacing, patch geometry and feed position. The designs have been simulated in the high frequency structure simulator (HFSS) environment in combination with a home-made GA code in MS Windows operating system. The GA operation is written using Visual Basic Script (VBS) Writer and the VBS file is called into the HFSS environment to perform simulations. The designs are checked for their fitness continuously until the termination criteria as set in the VBS code is reached.

\section{ANTENNA CONFIGURATION AND GA}

The patch array consists of two elements, where the size of a single element is fixed to fit in an area of 20 $\times 20 \mathrm{~mm}^{2}$. The objective is to maximize the directivity within that area. The patch array is etched on a thin substrate with a thickness of $1.52 \mathrm{~mm}$. The substrate material is Rogers RO4003 (tm), which has a relative permittivity of 3.38 and a loss tangent of 0.0027 . The antenna is fed by a $50 \Omega$ coaxial cable with a probe diameter of $1 \mathrm{~mm}$.

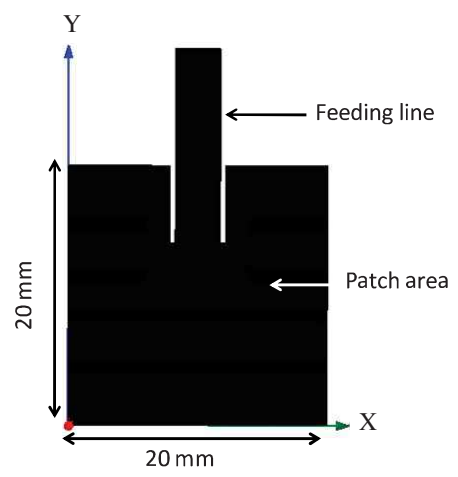

(a)

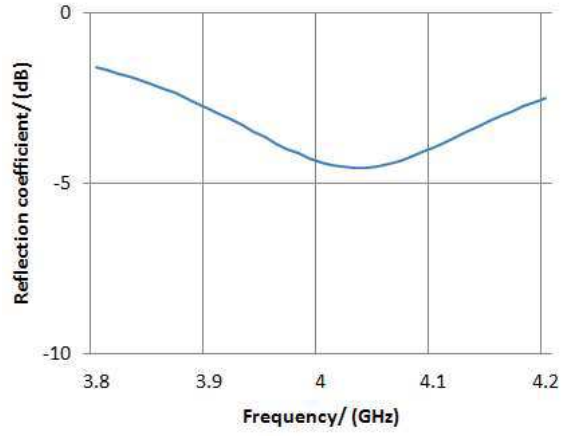

(b)

Figure 1: Simulation results of a single patch element. (a) Patch geometry; (b) $\mathrm{S}_{11}$ Plot

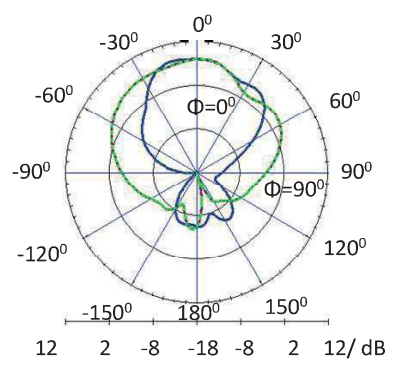

(a)

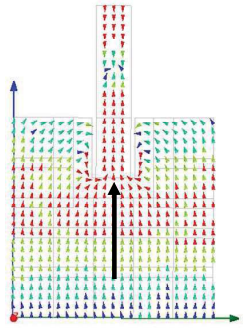

(b)

Figure 2: Simulation results of a square shaped patch. (a) Main radiation cuts at $4 \mathrm{GHz}$; (b) current distribution at $4 \mathrm{GHz}$ (the black arrow indicates the direction of current) 


\section{Single patch element}

Before starting the GA optimization process, a single patch element (size of $20 \times 20 \mathrm{~mm}^{2}$ ) is briefly analyzed for comparison purposes (Figure 1a). When the inset feeding length is $5.5 \mathrm{~mm}$, the antenna resonates at $4 \mathrm{GHz}$ in the fundamental mode (Figure 1b).

The radiation patterns and the current distribution of the square shaped patch are shown in Figure 2. At the fundamental $\mathrm{TM}_{01}$ mode, the directivity is only $7.1 \mathrm{~dB}$ in the broadside direction.

The basic method to improve the directivity is to use arrays. In this paper instead of using a conventional array, an optimized array is introduced. The next section explains the GA procedure employed to search for the right geometry to increase the directivity in the broadside direction.

\section{GA procedure}

To show the potential advantages of the proposed method, an array consisting of two identical elements is optimized in terms of element geometry, feeding position, and inter-element spacing. With this illustrative example, the method can be expanded to arrays with a large number of elements. The patch area in each element $\left(20 \times 20 \mathrm{~mm}^{2}\right)$ is divided into 23 cells so as to overlap between adjacent cells (Figure 3 ). The conducting or nonconducting property of each cell is defined using binary

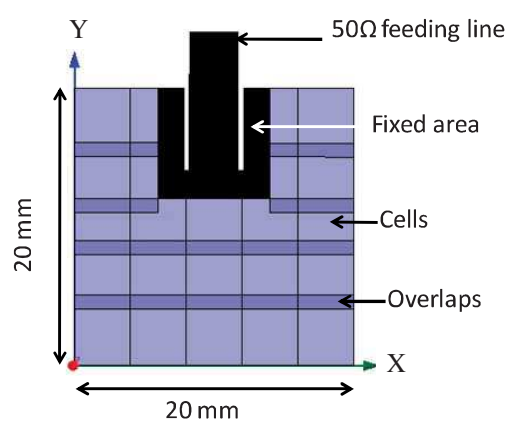

Figure 3: Cell distribution of the patch

Table 1: Format of the chromosome

\begin{tabular}{lllllll}
\hline Parameter & Patch geometry & $\begin{array}{c}\text { Inset feeding } \\
\text { length }\end{array}$ & $\begin{array}{c}\text { Inter-element } \\
\text { spacing }\end{array}$ \\
\hline $\begin{array}{l}\text { Corresponding } \\
\text { genes }\end{array}$ & $0,1,2,-------, 2^{2} 2$ & 23 & 24 & 25 & 26 & 27 \\
\hline
\end{tabular}

encoding. If a cell is conducting, then the corresponding gene is assigned ' 1 ' and if a cell is non-conducting, it is assigned ' 0 '.

Thus, the first 23 genes in the chromosome define the patch geometry and three more genes are used to define the inset feeding length. Different inset feeding lengths are used to select the best length for impedance matching. The final two genes define the inter-element spacing. The inter-element spaces are 4, 5, 6 and $7 \mathrm{~cm}$, which are $0.53,0.66,0.8$ and $0.93 \lambda$, respectively with regard to $4 \mathrm{GHz}$. Therefore, the chromosome consists of 28 genes as shown in Table 1. For example, considering the genes for inter-element spacing, if they are 00, 01, 10 , and 11 , the element spacing is $0.53,0.66,0.8$ and $0.93 \lambda$, respectively. Larger values are not recommended to avoid grating lobes.

The solution space consists of $2^{28}$ solutions (nearly $268 \times 10^{6}$ ) that would take a long time for a brute force method to analyze all the solution space. For example, if 1 minute is needed to simulate one solution, the overall time to analyze the whole solution space would be 510 years, where the GA takes only hours to find a solution.

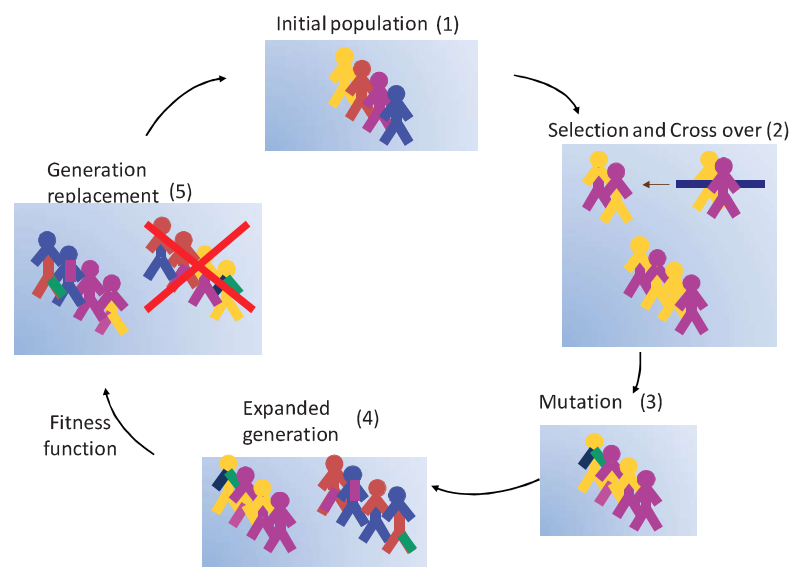

Figure 4: GA antenna design procedure

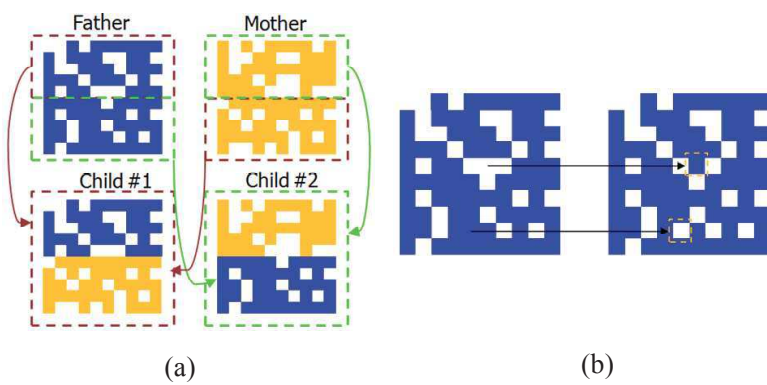

Figure 5: GA operations (a) Crossover (two children are generated from their parents); (b) Mutation (few bits are mutated) 
In the GA optimization procedure, the chromosomes go through three phases; initiation, reproduction and generation replacement (Figure 4). During initiation, 20 chromosomes are created randomly as the population size should be large enough to effectively create the next generation, and on the otherhand, it should be small enough to handle practically. Reproduction phase produces a new generation, which consists of 20 chromosomes from the current generation. A pair of individuals from the current population is selected to act as parents through random pairing. Then the operations called crossover and/or mutation are applied on the parents to produce the new generation. In the generation replacement phase, the new generation replaces the previous generation as the least fit individuals are removed from the expanded generation until it reduces to the normal population size (20). Thus the new generation is formed from the best individuals in the new generation and parent generation.

Table 2: Performance of Square patch array and the GA optimized patch array

\begin{tabular}{lcc}
\hline Parameter & $\begin{array}{c}\text { Square } \\
\text { patch array }\end{array}$ & $\begin{array}{c}\text { GA optimized } \\
\text { patch array }\end{array}$ \\
\hline Resonant freq./ $(\mathrm{GHz})$ & 4 & 4 \\
Directivity along $=0^{\circ} /(\mathrm{dB})$ & 9.6 & 10.9 \\
\hline
\end{tabular}

The GA optimization procedure consists of three natural inspired operations; selection, crossover and mutation (Figure 5). The selection method used in this study is the binary tournament selection. During crossover, genes of a randomly selected pair of individuals are exchanged in order to create the individuals of the next generation. Thus, two members of the new generation are created from two parents. In the GA procedure, the probability of crossover is $100 \%$, and single point crossover method is used. The crossover point is selected randomly. In binary representation, mutation operator changes a ' 0 ' to ' 1 ' and vice-versa. This operator allows the introduction of new chromosomes to the population and it assures that the entire search space is connected. The probability of mutation is $3 \%$ and the mutating genes are selected randomly. The simulations are carried out until convergence of fitness is achieved.

The fitness function includes the reflection coefficient and the directivity perpendicular to the patch at the resonant frequency. As the reflection coefficient is negative, while the directivity is positive, the fitness function $F$ is organized as shown in equation (1) to make this a maximization problem.
$F=D-L$,

where $D$ is the directivity perpendicular to the patch in $\mathrm{dB}$ and $L$ is defined as

$L=\left\{\begin{array}{cc}\rho & \rho \geq-10 d B, \\ -10 d B & \rho<-10 d B,\end{array}\right.$

where $\rho$ is the reflection coefficient in $\mathrm{dB}$ at the resonant frequency. As per the objectives of this study, this fitness function is maximized for a solution with the highest possible directivity at the resonant frequency.

\section{HIGH-DIRECTIVITY ARRAY}

\section{Optimized patch array}

For the simulations, an Intel Core i7 processor with $2 \mathrm{GHz}$ speed and a RAM with $6 \mathrm{~GB}$ capacity was used. The optimized design is obtained after about 40 generations and it is checked for another 20 generations to confirm the convergence of fitness. It consumed about 50 hours to run all 60 generations. As mentioned above, it was interesting to note that using an exhaustive method such as considering all the possible simulations without using GA, would be impractical. If each simulation takes 1 minute, it would take approximately 500 years to search all the antenna geometry space. Future work may be focused on running this procedure in UNIX machines.

The optimized design has an inter-element spacing of $0.8 \lambda$ and resonates at $4 \mathrm{GHz}$ (Figure 6). It is worth noting that the inter-element spacing is not the largest among the four possible values, which is $0.93 \lambda$. The reason is that the GA has found a solution that minimizes grating lobes. Naturally, the method can be expanded to include more inter-element values. However, for the sake of showing the potential of the method, only four interelement values have been proposed here.

The $-10 \mathrm{~dB}$ impedance bandwidth is $50 \mathrm{MHz}$. At the resonance frequency it has a broadside directivity of $10.9 \mathrm{~dB}$ (Figure 7a). The current distribution of the GA optimized patch is mainly parallel to the $\mathrm{x}$ axis and some areas have in-phase currents, which is the reason for the broadside radiation (Figure $7 b$ ).

\section{Conventional patch array}

In order to determine the benefits of the aforementioned design, a conventional $1 \times 2$ microstrip patch array was designed (Figure 8). The array, operating in its fundamental mode, fed in phase and spaced around 
(a)

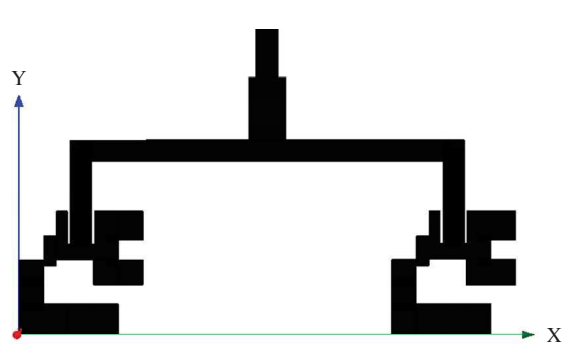

(b)

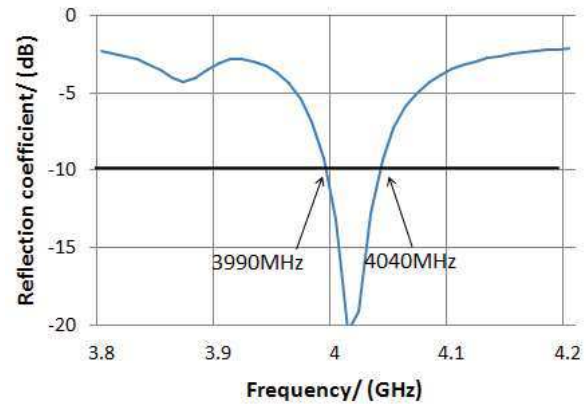

Figure 6: Performance of the optimized patch. (a) Patch geometry; (b) $S_{11}$ plot

(a)

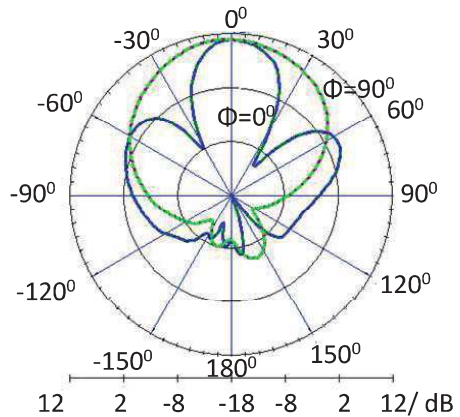

(b)

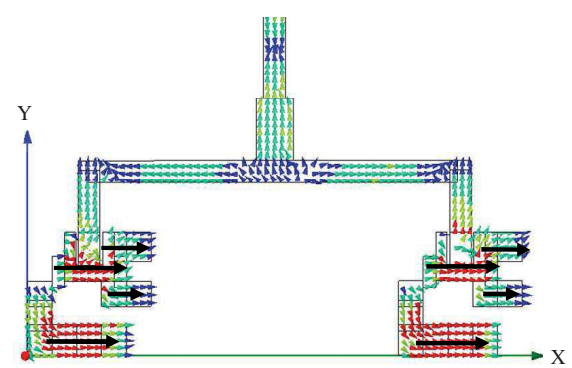

Figure 7: Performance of the optimized patch. (a) Main radiation cuts at $4 \mathrm{GHz}$; (b) current distribution at $4 \mathrm{GHz}$ showing the in-phase portions (the black arrow indicates the direction of current)

(a)

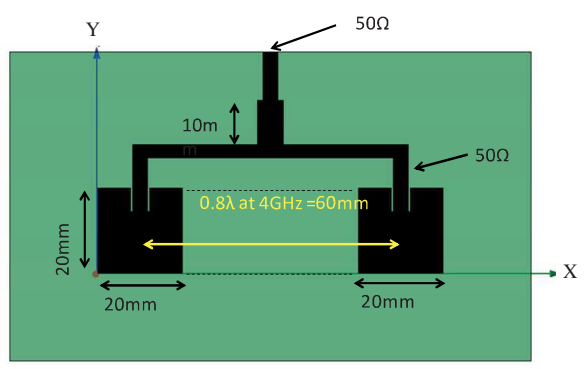

(b)

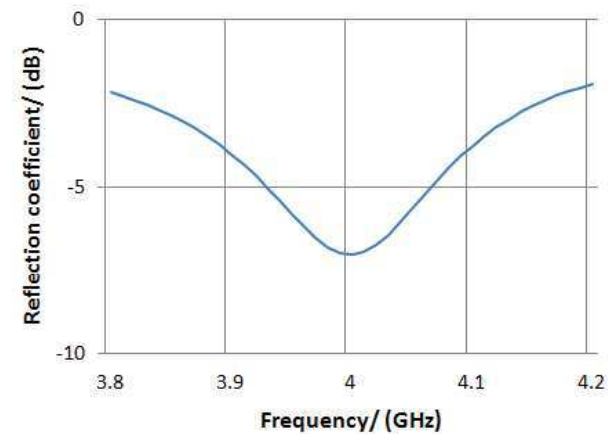

Figure 8: Performance of the $1 \times 2$ microstrip patch array. (a) Patch geometry; (b) $\mathrm{S}_{11}$ plot

(a)

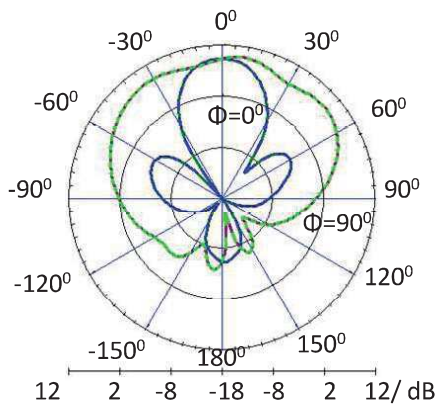

(b)

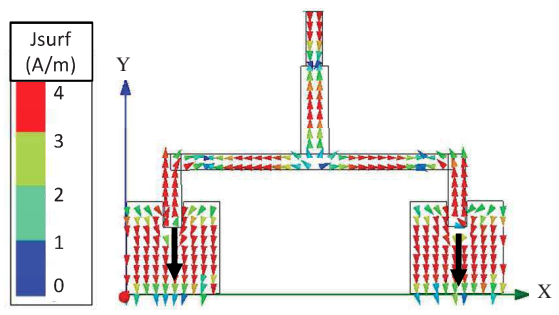

Figure 9: Performance of the $1 \times 2$ microstrip patch array. (a) Main radiation cuts at $4 \mathrm{GHz}$;

(b) current distribution at $4 \mathrm{GHz}$ (the black arrow indicates the direction of current) 
$0.8 \lambda$, provides a directivity of only $9.6 \mathrm{~dB}$ at $4 \mathrm{GHz}$ (Figure 9).

The GA optimized patch array is compared with an array of two square patches occupying the same area for the same frequency of operation. The results show that the genetic array has a larger directivity (1.3 dB more) and a better resonance behaviour (Table 2) indicating that it is possible to obtain a higher directivity by optimizing the patch geometry.

\section{CONCLUSION}

The GA optimization technique has been successfully used to improve the directivity of a patch array by having a directivity of $10.9 \mathrm{~dB}$ in the broadside direction. Comparison of the GA design with a conventional array of two square shaped microstrip patches showed that for the same area, the GA design achieves a $1.3 \mathrm{~dB}$ increment in the directivity. The method proposed here can be expanded to arrays with large number of elements.

\section{REFERENCES}

1. Anguera J., Puente C., Borja C., Montero R. \& Soler J. (2001). Small and high directivity bowtie patch antenna based on the Sierpinski fractal. Microwave and Optical Technology Letters 31(3): 239 - 241.

DOI: http://dx.doi.org/10.1002/mop.1407

2. Anguera J., Montesinos G., Puente C., Borja C. \& Soler J. (2003a). An undersampled high-directivity microstrip patch array with a reduced number of radiating elements inspired on the Sierpinski fractal. Microwave and Optical Technology Letters 37(2): 100 - 103.

DOI: http://dx.doi.org/10.1002/mop.10836

3. Anguera J., Puente C., Martínez E. \& Rozan E. (2003b). The fractal Hilbert monopole: a two-dimensional wire. Microwave and Optical Technology Letters 36(2): $102-104$. DOI: http://dx.doi.org/10.1002/mop.10687

4. Anguera J., Boada L., Puente C., Borja C. \& Soler J. (2004). Stacked H-shaped microstrip patch antenna. IEEE Transactions on Antennas and Propagation 52(4): $983-993$.

DOI: http://dx.doi.org/10.1109/TAP.2004.825812

5. Anguera J., Daniel J., Borja C., Mumbrú J., Puente C., Leduc T., Laeveren N. \& Roy P.V. (2008). Metallized foams for fractal-shaped microstrip antennas. IEEE Antennas and Propagation Magazine 50(6): 20 - 38 . DOI: http://dx.doi.org/10.1109/MAP.2008.4772718

6. Balanis C.A. (2005). Antenna Theory and Design. $3^{\text {rd }}$ edition. John Willey \& Sons Inc., USA.

7. Borja C., Font G., Blanch S. \& Romeu J. (2000). High directivity fractal boundary microstrip patch antenna. IEE Electronic Letters 36(9): 778 - 779.
DOI: http://dx.doi.org/10.1049/el:20000625

8. Cheype C., Serier C., Thèvenot M., Monédière T., Reineix A. \& Jecko B. (2002). An electromagnetic bandgap resonator antenna. IEEE Transactions on Antennas and Propagation 50(9): $1285-1290$.

9. Coevorden C.M.D.J.V., Garcia S.G., Pantoja M.F., Bretones A.R. \& Martín R.G. (2005). Microstrip-patch array design using a multiobjective GA. IEEE Antennas and Wireless Propagation Letters 4: 100 - 103.

DOI: http://dx.doi.org/10.1109/LAWP.2005.845907

10. El-Khouly E., Ghali H. \& Khamis S.A. (2007). High directivity antenna using a modified peano space-filling curve. IEEE Antennas and Wireless Propagation Letters 6: $405-407$.

DOI: http://dx.doi.org/10.1109/LAWP.2007.903492

11. Feng P., Xing C., Ren X.Y., Liu C. \& Huang K. (2013). A novel microstrip grid array antenna with both high-gain and wideband properties. Progress in Electromagnetics Research C 34: 215 - 226.

DOI: http://dx.doi.org/10.2528/PIERC12082920

12. Foroozesh A. \& Shafai L. (2012). On the characteristics of the highly directive resonant cavity antenna having metal strip grating superstrate. IEEE Transactions on Antennas and Propagation 60(1): $78-91$.

DOI: http://dx.doi.org/10.1109/TAP.2011.2167933

13. Haupt R.L. (1995). An introduction to genetic algorithms for electromagnetics. IEEE Antennas and Propagation Magazine 37(2): $7-15$. DOI: http://dx.doi.org/10.1109/74.382334

14. Jayasinghe J.W., Anguera J. \& Uduwawala D.N. (2013a). A high-directivity microstrip patch antenna design by using genetic algorithm optimization. Progress in Electromagnetics Research C 37: $131-144$.

DOI: http://dx.doi.org/10.2528/PIERC13010805

15. Jayasinghe J.M.J.W., Anguera J. \& Uduwawala D.N. (2013b). Genetic algorithm optimization of a highdirectivity microstrip patch antenna having a rectangular profile. Radioengineering 22(3): $700-707$.

16. Jain R. \& Mani G.S. (2011). Dynamic thinning of antenna array using genetic algorithm. Progress in Electromagnetics Research B 32: 1 - 20.

DOI: http://dx.doi.org/10.2528/PIERB11042203

17. Laseetha T.S. \& Sukanesh R. (2011). Synthesis of linear antenna array using genetic algorithm to maximize sidelobe level reduction. International Journal of Computer Applications 20: 27 - 33 .

18. Mitilineos S.A., Papagianni C.A., Verikaki G.I. \& Capsalis C.N. (2004). Design of switched beam planar arrays using the method of genetic algorithms. Progress in Electromagnetics Research 46: $105-126$.

DOI: http://dx.doi.org/10.2528/PIER03080802

19. Paras \& Gangwar R.P.S. (2011). Design of compact and multiband antenna array using genetic algorithm optimization. International Journal of Microwave and Optical Technology 6(4): 221 - 227.

20. Patel K. \& Alad R. (2013). Side lobe level optimization of planar phased array antenna using genetic algorithm. International Journal of Emerging Trends in Electrical and Electronics 2(4): 48 - 52. 
21. Pirhadi A., Bahrami H. \& Nasri J. (2012). Wideband high directive aperture coupled microstrip antenna design by using a FSS superstrate layer. IEEE Transactions on Antennas and Propagation 60(4): 2101 - 2106.

DOI: http://dx.doi.org/10.1109/TAP.2012.2186230

22. Rodríguez J.A., Ares F., Palacios H. \& Vassal'lo J. (2000). Finding defective elements in planar arrays using genetic algorithms. Progress in Electromagnetics Research 29: $25-37$.

DOI: http://dx.doi.org/10.2528/PIER00011401

23. Romeu J., Borja C. \& Blanch S. (2000). High directivity modes in the Koch Island fractal patch antenna. IEEE Antennas and Propagation Symposium, pp. $1696-1699$.

24. Siakavara K. (2010). Novel fractal antenna arrays for satellite networks: circular ring sierpinski carpet arrays optimized by genetic algorithms. Progress in Electromagnetics Research 103: 115 - 138.

DOI: http://dx.doi.org/10.2528/PIER10020110

25. Tokan F. \& GÄunes F. (2009). The multi-objective optimization of non-uniform linear phased arrays using the genetic algorithm. Progress in Electromagnetics Research
B 17: $135-151$.

DOI: http://dx.doi.org/10.2528/PIERB09072309

26. Weily R., Bird T.S. \& Guo Y.J. (2005). A reconfigurable high-gain partially reflecting surface antenna. IEEE Transactions on Antennas and Propagation 56(1): $3382-3390$.

27. Yang H.D., Alexopoulos N.G. \& Yablonovitch E. (1997). Photonic band-gap materials for high-gain printed circuit antennas. IEEE Transactions on Antennas and Propagation 45(1): $185-187$.

DOI: http://dx.doi.org/10.1109/8.554261

28. Zhou H., Pei Z., Qu S., Zhang S., Wang J., Duan Z., Ma H. \& Xu Z. (2009). A novel high-directivity microstrip patch antenna based on zero-index metamaterial. IEEE Antennas and Wireless Propagation Letters 8: 538 - 541. DOI: http://dx.doi.org/10.1109/LAWP.2009.2018710

29. Zhu X., Shao W., Li J.L. \& Dong Y. (2012). Design and optimization of low RCS patch antennas based on a genetic algorithm. Progress in Electromagnetics Research 122: $327-339$.

DOI: http://dx.doi.org/10.2528/PIER11100703 